\title{
Managing fat bodies: Identity regulation between public and private domains
}

\begin{abstract}
Summary
This paper analyzes the relationship between public and private domains in contemporary Danish organizations by examining their increasing focus on the personal health situation of employees, and, more specifically, their body weight. This paper combines literature on identity and management with governmentality-inspired research on risk, morality and the body. The aim of this paper is to show that overweight people are perceived as "risk identities", i.e. problem people who automatically call for personal management. The author demonstrates that besides the unintended effect of categorizing overweight employees as problem people, this management goal also run counter to the declared value regarding respect for diversity in contemporary organizations. Based on in-depth interviews with managers and recorded talks between health consultants and overweight employees, this paper emphasizes processes that subordinate employees and restrict their autonomy.
\end{abstract}

\section{Introduction}

Western societies are witnessing a shift in the object of management's attention. The modernization of the welfare state not only involves a shift in power structures (from state to market), but also a shift of responsibility from public to private domains (Newman, 2007 , p. 27). A focus on the citizen/employee's personal and private life, including body weight, has become increasingly common in both public and private work organizations. This paper focuses explicitly on the regulation of overweight employees by work organizations, with particular attention to the relationship between public and private domains.

The field of gender studies has long been concerned with the separation of public and private domains. Some discussions have focused upon the complexity of the categories public and private (e.g. Gavison, 1992), and have looked at the binary thinking reflected in this division (e.g. Linstead \& Brewis, 2004). Others have focused their critique more specifically on the way the division public-private reflects male-female qualities, thus encouraging the marginalization of in particular women's qualities in public domains (e.g. Lister, 1997, 2001) and in organizational theory in general (Wilson, 1996).

However, bringing the two domains together and thus securing room for both the personal and the private in public domains has also been raised in recent studies. These studies show that "emotional, self-reflexive relations" - in the workplace, for example - may ultimately have an oppressive effect, just as more bureaucratic and impersonal work relations can empower (Ashcraft, 2000, p. 380; see also Brewis et al. [1997], for a critical discussion of the "feminization" and "re-eroticization" of the workplace). "If the personal is politicised, or the political personalised, the public and private domains are both likely to 
be twisted out of shape" (Marquand, 2004, p. 80 quoted in Newman, 2007, p. 32-33). In this paper, I present empirical material in support of this argument.

This paper demonstrates that converting a private, personal matter such as body weight into a public concern can have anything but a liberating effect on overweight employees. In other words, publicly motivated forms of caring for overweight employees are not like forms of caring as we know them from the private domain (see also Casey [1999], for a critique of metaphors such as "family" in organizations). Consequently, the categories public and private have been "twisted out of shape" in attempts to "manage" employees' weight.

As a subject for research the overweight body has been neglected within organizational studies. A review of the existing literature on bodies and organizations indicates that the conspicuously overweight body is even more of "an absent presence" in organizational studies (Barry \& Hazen, 1996 in Hassard, Holliday \& Willmott, 2000, p. 4; Valentine, 2002) than the gendered or sexual body (for an exception see Trethewey, 1999). In regard to the overweight body there is much that organization theorists would do well to improve their understanding of. The new managerial object - the unhealthy body - imposes new conditions on management, thus raising an important question about the way managers' deal with the demarcation between the public and private domains in their organizations as they strive for healthy employees.

As well as drawing attention to managerial practices concerning the overweight employee (and thus securing more attention for this "absent presence" in contemporary organizational research), I aim to contribute to critical research on the public-private relationship by focusing on the possibly negative aspects of "helping" and "caring" organizations. A related topic here concerns the necessity of bridging the gap between organizational stud- ies of practice and governmentality-inspired studies of risk, morality and the body. It is my hope that bringing these two approaches together will 1) show how employees, managers, organizations and society exist in a mutually dependent relationship (Kärreman \& Alvesson, 2004, p.150), and 2) enable a focus on the physical body in organizational life.

\section{Background information}

According to the World Health Organization (WHO) (2006a, item 1), "obesity in Europe has reached epidemic proportions" and is therefore believed to be "one of the greatest public health challenges of the $21^{\text {st }}$ century" (www.euro.who.int/obesity). Half of all adults in the WHO European Region are overweight, something that is believed to have a considerable effect on economic and social development (WHO 2006b). In the case of Britain, for example, the English National Audit Office estimates that the indirect cost of obesity in England amounts to $£ 2$ billion a year, including 18 million days lost due to illness and 40,000 working years lost due to the high mortality rate among overweight persons (National Audit Office, 2001). In Denmark, the same trend is emerging, prompting Danish politicians to propose a variety of programs to deal with the problem. National health plans have been developed stressing that counteracting obesity and overweight in the population is a multi-sector responsibility involving government initiatives, private and public work organizations, schools, etc. (Danish Ministry of the Interior and Health, 2002). Denmark is thus working in line with WHO's recommendation to take action at both the micro and macro levels by involving "families, communities, kindergartens, schools, workplaces" in counteracting obesity and overweight (2006b, p. 4).

To confront the increase in the number of overweight people in Denmark, many work organizations have begun to focus on the risks in- 
volved in the lifestyle of overweight people. A variety of measures have been taken involving pedometers, healthy food in the cafeteria, exercise rooms, consultations with dieticians and much else. This focus is a result of government initiatives (the actual activities are often partly or wholly financed by the state) and of the new way in which work organizations brand themselves, i.e. by highlighting activities that focus on employee health. Motivated by a broad range of social concerns, contemporary work organizations are developing strategies for reducing the number of overweight employees.

One of the more popular strategies is the "personal health talk" that takes place between an individual employee and a health consultant. This talk is part of a politically motivated strategy aimed at reducing the number of people at risk of becoming sick. In these talks, the employees explain their lifestyle, e.g. eating, smoking and drinking habits, as well as their psychological state, while the health consultant offers advice about ways in which the employee concerned could improve their health. In conclusion the two parties sign a contract stating that the employee will try to work at a healthier lifestyle in the future.

Courses are available for managers on how best to conduct such talks. My own research on the way they were being conducted in different organizations revealed no one specific right way of doing it. Private firms generally hire health consultants to conduct such talks, whereas public organizations generally educate members of staff to become health consultants. These talks and contracts have consequences far beyond their intended effect on the individual employee's health situation. First, on the organizational level, the idea of building a uniform (slim) workforce contradicts an oft-publicized goal about respecting diversity. Second, on the individual level, the focus on overweight employees as people needing to change their lifestyle - often despite their currently healthy condition - means imposing 'client' identity on someone who is in fact a healthy, self-supporting individual. Moreover, as Loseke (1999, p. 160) astutely notes, "To be a client is, by definition, to be a person in need; to be a person in need is also to be a weak person" (emphasis in the original).

\section{Being "at risk"}

The growing negative focus on being overweight is of course related to the increase in obesity in Western countries, but this might not be the entire explanation as to why this particular group attracts so much attention as it does today. The greater focus on risks in contemporary Western societies, including lifestyle risks, may also explain some of the current focus on the overweight. Governmentality-inspired studies on risk, morality and the body (e.g. Douglas, 1992; Lupton, 1999a, 1999b; Dean, 1999a; Novas \& Rose, 2000; O’Malley, 2000; Ericson \& Doyle, 2003) can therefore help to further the debate on why the average employee in contemporary organizations is not supposed to be overweight.

According to Novas and Rose (2000) we are witnessing the emergence of a new type of human being: the somatic individual. The somatic individual is defined primarily in terms of the body and the body is considered these days to be the site where any number of dangerous elements may converge. People are exposed to many types of risk in their daily lives today, including the medical and lifestyle kinds. Consequently, people are being identified according to their risk profile, i.e. the variety of factors to which their bodies may be said to be exposed. Despite a clean bill of health the body is considered to be potentially sick and thus always, in some sense at least, in need of care. Overweight people have consequently become particularly visible in recent years: the very physical appearance of this group demonstrates that they are "at risk" of developing a varied range of illnesses. 
As Lupton notes, being "at risk" is to be "located within a network of factors drawn from observations of others" (2005, p. 93). "To be designated 'at high risk' compared with others is to be singled out as requiring expert advice, surveillance and self-regulation" (Lupton, 1999b, p. 61). Although the somatic individual, i.e. one with an "at-risk" identity, implies only a potential problem (one that has not yet developed, and may never do so), the "at-risk" identity itself naturally calls for management. Consequently, at-risk people are doubly exposed: first to the dangers of the natural environment and, second, to the interpretation of their social environment.

In the governmentality literature it is argued further that individual subjects in neo-liberal societies are presumed to have a self-restraining and self-governing capacity. Neo-liberalism is a political strategy that emphasizes responsibility, will power and active subjects (e.g. Rose, 1996; Dean, 1999b). The state thus becomes an agent that uses an "indirect technique for leading and controlling individuals" (Lemke, 2001, p. 201), for example by establishing (new) laws in the health field that require organizations to regulate their employees' personal health situation. One characteristic of the neo-liberal state (such as contemporary Western society) is that it tries to free itself from some of its responsibilities by addressing the citizen as an "active partner in the drive for health, accepting their responsibility for securing their own well-being" (Rose, 2001, p. 6). The role of the government and of organizations with health strategies at their workplaces is thus to provide advice and assistance to active, free citizens, enabling these in turn to engage in risk-avoidance behavior (Lupton, 2005, p. 100).

Once organizational practices are regarded as embedded in dominant norms and values in society, overweight people automatically provoke reactions based on neo-liberal values, such as the capacity for self-restraint and self-governance, will power, responsibility and control. These morally embedded standards are articulated in neo-liberal risk discourse - in politics and in the media - and compel overweight people to lose weight - or at any rate to look upon their weight as a problem. The risk discourse thus defines overweight people as individuals who ought to desire a change in their (problematic) situation. This is a double process that constructs a "normal" identity, which at the same time defines the overweight person as being "at risk" (as abnormal). And, as Lupton (1999a, p. 4) notes, normalization is a central aspect of liberal governance in which determining a citizen's health status becomes vital.

The governmentality-inspired research on risk, morality and the body sees bodily control as tantamount to social control. A fat body is a body that demonstrates a lack of personal control and consequently challenges the prevailing social order. What falls "in-between" represents the impure, contaminated and risky (Douglas, 1966). According to Lupton, "The 'civilized' body is that which is self-contained, tightly regulated, dry and proper...it is a cultured body distinct from the natural. The 'grotesque' body, in contrast, is that which is unregulated, its boundaries liquid ... closer to 'nature' than to 'culture"' (1999b, p. 78).

Current concern about the possession of a overweight body may reflect not only the outright increase in the number of overweight people, but also the fact that the core values of Western societies, such as control, regulation and responsibility will naturally marginalize those individuals whose bodies are out of control, demonstrating "liquid boundaries" that fall "in between". In present day society being healthy - that is, being slim - is more than just an individual's right: health can also be regarded as a duty, enforced by subordination to authority (Greco, 2004, p. 2). The social figure "the somatic individual" thus implies that normality in present Western society revolves 
around the constant pursuit of health, freedom and happiness (Gordon, 1991). Consequently, people whose habits (such as smoking) or bodily characteristics (such as overweight) reveal a potential for their becoming ill can naturally be equated with people in need of management.

\section{Methodological reflections}

The focus of the present paper on identity constructions places my analysis within an anti-essentialist approach, which naturally also affects the status of my empirical material. All the texts included in the analysis are social texts: they should not be regarded as "pure data" in a more naturalistic sense (Gubrium \& Holstein, 1997; Mik-Meyer, 2009). The interview material should be seen as a result of an active encounter between the researcher (with his or her theoretically motivated research agenda) and the respondent (confronted by this agenda) (Holstein \& Gubrium, 1997; Järvinen, 2001; Silverman, 2003). Recorded interactions between health consultants and overweight individuals (referred to as talks in this paper) are likewise inscribed in a body of material selected by myself and analyzed in accordance with the theoretical focus in the present study on the formation of identities.

The following analysis draws on a two-year research project (2005-2007) concerned with the experience of being overweight in Denmark. A qualitative, ethnographic approach has been adapted in the main study consisting of participant observation, recorded talks between health consultants and overweight employees (which I did not attend), and interviews with managers, health consultants and overweight individuals. In the present analysis I have excluded interviews with overweight people and general observation material, although I am aware that this material illustrates other ways in which identities are constantly reproduced in different social settings. My choice of two types of empirical material reflects my desire to be able to work, in depth, with a large amount of material.

The empirical material presented below has been drawn from interviews with 10 managers and from 26 health talks between health consultants and overweight persons who had volunteered to participate in the talks concerned. The material was chosen in this way because the interviews shed light on the managerial problems involved in working with the "fat employee's" (as overweight people are often conceptualized as), ${ }^{1}$ whereas the recorded talks shed light on the way such work was actually carried out. Both methods (conducting interviews and analyzing the recorded talks) can shed light on the potential problems involved in working with private, personal issues in a public domain.

In the analysis I have been exceedingly attentive to the fact that I am dealing with research material of different kinds. Although the interviews were conducted in an open-ended way, this material can never be separated from the research process during which the interview guidelines etc. were developed. In analyzing the interview material, I have therefore been particularly attentive to any dialogue that (unintentionally) reflects the interviewer's own agenda rather than that of the respondent. The recorded talks, on the other hand, are not directly influenced by the researcher. Nevertheless, this material is also somewhat influenced by my researcher self, in that the actual taping of the talks took place as a necessary step in the research project (the participating individuals had of course agreed to have their talk recorded). Although the recording procedure is likely to have affected

1 I am using the terms "overweight" and "fat" in the paper interchangeable because both terms are commonly used by the persons carrying the extra kilos and by the firms that focuses on weight issues in their employees. 
the talk that took place, this material is likely to be less affected by the research agenda than the interview material.

I have excluded any dialogue from the talks that could have been interpreted as by the interviewer "forced" (if the interviewer, for example, kept leading the interviewee back to the some specific topic even though he or she did not have much to say about it). I have also omitted any dialogue that was atypical in terms of the nature of the material as a whole. In such a case, it was usually a question of dialogue regarding issues that rarely arose in the material as a whole.

\section{Manager interviews}

In order to analyze the relation between work organizations and overweight employees, and the way in which fat identities are "managed", I based my analysis on interviews with managers from ten large and medium-sized public and private organizations. The interviews were based on interview guidelines focusing on why the firm concerned had decided to confront issue of weight (problems). The interviews took up the managers' experiences of initiatives of this kind, and the way the employees had responded to the various activities focusing on their health. Interviews with the managers were open ended. The managers were all ethnic Danes. They included five men (two from public organizations and three from private organizations) and five women (three from public organizations and two from private organizations). Five of the managers had a professional background in HRM and five of them had qualified in a variety of fields (four of these last mentioned managers had medical backgrounds; one had originally trained as an electrician). Within the last one to seven years (most often one to three years) they had all held managerial positions in the health field, either as project managers in the organizations' health systems or as work environment or human resource managers. The interviews showed, among other things, that personal health talks were a favored method for learning more about overweight employees, which is why I decided to record them.

\section{Recorded talks between overweight employees and health consultants}

To be able to analyze how fat identities were being negotiated in practice, I made an analysis based on 26 recorded health talks. Because I wanted recordings that were not particularly influenced by my research, I contacted two organizations that had not previously been involved in my project, and obtained permission to record personal health talks there. One of these organizations was a large municipality in Denmark that offers personal health talks to its overweight employees. The employees came from a wide range of jobs in the municipality; the majority had secretarial jobs involving office work. The second organization was a project that was well established in a medium-sized municipality where it had become a standard offer for the municipality's overweight inhabitants. It had been running for several years offering a full time course for overweight persons, typically lasting 18 weeks, that targeting people on temporary leave of absence or those who had recently left the labor market. Weight issues were believed to be preventing them from getting their jobs back or, more generally, from re-entering the labor market. The overweight persons in both organizations received a letter about my research several days before the talk, stressing that their participation would be very welcome, but only with their consent. I also explained in the letter that participation was anonymous and that they could decide not to allow me to have the recording after the talk, if they changed their minds, although no one ever did.

Each recorded talks lasts for approximately one hour. I listened to them all twice. The first time round I made a note of the topics being 
discussed while the tape was playing; afterwards, I listened to them again in order to note specifically the topics I wanted to have transcribed. Long monologues from the health consultant on nutritional matters were generally omitted, while passages that favored dialogue between the two parties were transcribed by an expert. Approximately 20 - 40 minutes of each talk has generally been transcribed. Two people in both organizations were in their 60 s with the rest being in their 40 s or 50 s. They were all ethnic Danes. Twenty-two of the 26 overweight participants were women. It is beyond the scope of the present paper to focus on gender issues. Nevertheless, one interesting gender-oriented observation can be noted. As shown by many writers, research on the body and society has often implied that fat is a feminist concern (as the title of Susie Orbach's [1978] famous book, Fat is a feminist issue, proclaims). In other words, fat is primarily perceived as a problem for women. And in fact women are overrepresented in my own study, even though $40 \%$ of the men and only $26 \%$ of the women in Denmark are overweight (World Health Organization, 2006c, p.19). Overweight women are apparently more attracted (or believe they should be attracted) by the great range of activities aimed at losing weight. If the focus on body weight in the public domain is actually growing - as suggested by Trethewey (1999) - then we may find ourselves facing an even more powerful marginalization of women than extensive gender and feminist research has already established.

\section{Analysis 1: Managers' talks about overweight employees \\ "I felt it verged on bullying": Managers tackle their identity as health police}

All interviewed managers in the ten public and private organizations expressed concern about the health strategies targeting overweight people at their workplace. One female manager (A) in a private organization declared "our goal is not to line up Barbies and Kens in neat rows. Diversity is very important". Others worried that the new aspect of health management with its focus on the employee's weight would mean interfering too much in the private life of the individual. One male manager (B) in a private organization put it as follows:

Being overweight is something very personal. I felt it verged on bullying....also our policy is to focus on diversity in the company.... and fat people - for better or for worse - are part of the society we live in... So it's difficult to strike the right balance. Where do you draw the line?

However, since the managers all agreed that overweight are one of society's major problems, they declared such an approach to be necessary. As one female manager $(C)$ from a public organization put it, "We have this fatness epidemic...lifestyle disorders don't just affect the individual...they also affect the company and society as a whole". Many of the others agreed. One male manager (D) from a public organization declared that on this subject it was necessary to "take our kid gloves off":

\begin{abstract}
My agenda is to keep people at work... Why does the government produce a public health plan for the next ten years? Because in the long run weight is the biggest threat to our health... Our Company's efforts may do away with the need for early retirements... Of course we'll have to tell some people that they are risking their health, which of course, is not a very nice message. But we have to take our kid gloves off and talk about this subject.
\end{abstract}

Or, as a female manager (E) in a private organization put it:

Something like being overweight may feel like a private matter, but actually it isn't. People fall ill as a result of being overweight, and then they can't work...so their health really is a company matter... 
Many employees feel a sort of family relationship between the company and themselves, so they think it's quite okay [that their workplace takes an interest in their weight].

All the managers interviewed took up the question of the boundary between public and private when it comes to dealing with private issues (such as an employee's weight) in a public context (such as the workplace). The interviews demonstrate clearly that this new area of management produces the sort of ambivalence described by managers A, B, D and $\mathrm{E}$ above. However, because there is a widely held view that management should partake in this type of personal focus on the employee they generally overcome any sense of unease. Essentially, it is recognized that overweight people are at (serious) risk of developing a whole range of illnesses, and that this in turn represent a financial threat to society. Moreover, any remaining unease regarding the intimate nature of this focus is dealt with by emphasizing, referred to by manager $\mathrm{E}$, the "family relationship between the company and themselves" that many employees have.

\section{Working in a "sprit of dialogue": The definition of the problem}

Another theme that appears in many of the interviews, and that is also related to the "public/ private" issue, is that participation in the various programs is based on the employee's own free will - a point that seems to be of some importance to all the managers interviewed. Although most of the programs are dependent on the employee's voluntary participation, this does not solve a crucial problem - namely, that the employees' definition of their problems does not match the manager's perception of the employees' situation. In the interviews the managers explain in a variety of ways that their job is not to define the employee's problem. At the same time, it is their precise job to deal with unhealthy lifestyle issues - even when the individual employee does not see their lifestyle as a problem. The following quotation from $\mathrm{F}$ (a male manager in a private organization) illustrates the ambiguity embedded in the current health program:

We tackle health in a spirit of "dialogue" - openness - whereby we discover unison what is important to work on. The employee may say "I don't think I have any problems". This is a statement that is a hundred percent true, because it's the person's own opinion, and that's what counts. We can then counter, "We agree, but where eating vegetables is concerned, you're in the red". Or we may say, "We agree, but are there any hereditary factors to take into account?" Or we may say, "We agree, but is your cholesterol level above normal?" The outcome of this health check may actually be that people leave us a little bit sicker that when they came in. That is the paradox of screening.

Note how this manager begins every sentence by saying "we agree" (working in a "spirit of dialogue"), but he actually only does so to open the way for disagreement ("but [does the person...]"). The repetition of the response "We agree, but" three times in a row gives the impression that the manager will always be able to find something unhealthy or problematic in the employee's lifestyle that needs tackling. The fact that overweight employees become patients by definition (or at least are "at risk" of becoming sick) embraces to both the organizational and the societal contexts. The idea that the "overweight employee" identity implies "sick employee" can subsequently be seen as a socially constructed identity arising 1) from the organizational focus on excess weight as a factor that needs to be managed (this assumption is backed up by the availability in the organization of the many strategies) and 2) from the governmental focus on excess weight as a major threat to society (as manager E explained).

Manager $\mathrm{F}$ also commented on the social identity implicit in being overweight when he 
talked about the paradox that screening establishes the screened person as "sick". The interviews show the contours of Nova and Rose's somatic individual, i.e. a personality construed primarily in terms of the body, which is increasingly regarded as the focus for various illnesses, despite a clean bill of health from the last visit to the doctor. After all, the health consultant does not classify the employees as healthy: he simply runs a test to determine the variety of ways in which they might be sick. As manager F puts it, "people leave us a little bit sicker than when they came in".

\section{"Fat people lack the resources to take responsibility": Teaching responsibility}

The interviews all put great emphasis on the responsibility of the individual overweight employee for their own work life and their own personal situation. $\mathrm{G}$, a male manager in one private organization explained:

\footnotetext{
We want the individual employee to take the greatest possible responsibility for his own work life and his personal situation...his fatness. We seek a two-way attitude that implies, "I am aware of, $I$ have a big investment in - whatever it may be, career or fatness - solving my problem...you have to choose, you can't expect someone else to solve your problems"... But the difficulty with fat people is that their self-esteem is low and they probably lack the resources to take responsibility for their situation... this group [thus] needs our help.
}

The definition of the employee as someone, who should have the drive to change their own situation, i.e. take responsibility for their own life, dominates neo-liberal society and appears in all the interviews. Manager $\mathrm{G}$ emphasizes that the individual employee (referred to as "I", “my”, “you”, “your") has to be able to take personal responsibility and to solve their own problems themselves. But note that he also says that fat and overweight people cannot be expected to possess this ability because of their low self-esteem (a common conviction among managers). With this assumption that part of the problem is a psychological weakness, i.e. not being able to act responsibly, Manager $\mathrm{G}$ has thus produced an argument for exercising more control over this specific group. By converting the target for help (a person's weight) into a psychological problem (the person is irresponsible and out of control) endows the managers more control: the new identity for overweight employees implies that they are people you cannot trust.

Goffman (1968) showed that situations like this had the unfortunate result of reinforcing the asymmetrical relation between the helper and helped, thus strengthening the ties of control. Because the employees' weight problems have been converted into a psychological abnormality that makes them untrustworthy as "dialogue" partners, any resistance on their part will legitimize the very "help" (that has caused the resistance). My interviews clearly show that overweight employees who did not connect their weight problem with a psychological defect, were believed by the health consultants to suffer from even more serious psychological problems. This process is framed by the discourse of denial in the socalled "troubled person industry": the more you deny the identity that your organization proposes for you, the more its staff will believe that identity to be correct (Loseke, 1999).

\section{Analysis 2: Developing the fat identity in health talks}

\section{"Cotton candy willpower" and "the [bad] voice inside you": Creation of the fat identity for overweight employees}

The following passages have been selected from the transcripts of two personal health talks and they exemplify common issues and techniques that occurred in all the talks recorded. A frequent topic was the overweight employee's willpower, or its absence. Another common feature of the talks was the health consultant's 
elicitations of very detailed answers. There were often long detailed discussions on such topics as what the employees ate, who cooked their meals and where they shopped. Matters of a psychological nature (discussions about willpower, for example) were usually introduced in a remarkably concrete and vivid manner. Concrete exemplifications and role play often occurred in the recorded talks. For example, the overweight person might be asked to play their real life-partner, while the health consultant played the overweight person. In the course of such games the consultant would adjust the questions and answers according to what the overweight person thought they would have said in such a real-life situation. I have chosen passages from talks with one male and female overweight person. The first excerpt shows how a weak-willed employee is constructed.

\section{Constructing a weak-willed employee}

Health consultant: That cookie is always beckoning you... and if you want to cope with that, you'll have to give your willpower a bit of space... Where is your willpower inside you? Where? Is it in your knee? In your side or your back, where is it...?

Peter: I'm damned if I know. I never thought of it like that...?

Health consultant: No, I know it's an abstract way to think about it, but I would like you to try anyway, try to think about where it's located. Think about when you quit smoking, where was it then?

Peter: In the upper part of my body...

Health consultant: If you had to describe things from that time, and let's say it had a color, what color would it have had then?

Peter: Well, I don't think it's that easy to think about it in colors. I'm not capable of doing that...
[The health consultant continues to direct the talk towards an exact physical description of Peter's willpower. For instance she asks whether it's dark or light, whether it's has one color or several, whether it's "a hard lump inside you" or whether it's "soft or crispy". Peter is a bit reserved when he answers, saying things like "hmm" or "I don't quite get it", showing that it is difficult for him to follow her line of thought. Together, they define his willpower at the time he stopped smoking as resembling "cotton candy" (the exact term is suggested by the health consultant). The health consultant draws on the cotton candy imagery as the talk continues.]

Health consultant: Well, if you had to describe your willpower at the time you quit smoking, did it take up all the room in your upper body, this cotton candy-like willpower, or did it take up half your upper body, or...?

Peter: No, I think it took up a quite a bit of room.

Health consultant: (pause) Okay.

Peter: But, it was also because I was affected by avoiding these things all the time, right?

Health consultant: If you think about your willpower today, in general, in relation to the things you do. How much space do you think it would occupy today, your cotton candy, yellow, blue, green, pale, light-weight...?

Peter: Well, it doesn't take up much room... Health consultant: Hmm...

First, the passage above shows that this talk - like all those in my project - is part of a general social-psychological, anti-fat discourse, thus making topics such as willpower legitimate subjects of discussions (Greco, 2004). Second, the employee is gradually transformed into a weak-willed individual a status confirmed by his own words: "Well, 
[my willpower] doesn't take up much room". By accepting the institutional identity of a weak-willed individual, he becomes a person with whom the health consultant can work. Third, the health consultant's suggestion that the employee's willpower is located in some marginalized part of the body ("knee", "side" or "back") rather than in parts that usually define who we are (heart or head), confirms the analysis that the health consultant essentially offers the employee a weak-willed identity. This is also supported by the health consultant's discouraging response (pause, “okay") when Peter suggests that he once had enough willpower to occupy "a reasonable amount of space". The health consultant's answer triggers Peter's elaboration and documentation of why he thinks he once had willpower ("But, it was also because...").

At other points in the talk, the consultant takes up the employee's ability to control his food consumption - something that leads on to the question of the strength of willpower. The consultant's interest in Peter's willpower and what he can do to strengthening it is a recurring topic suggesting that his (lack of) willpower thus seems to be a general problem that needs to be tackled. This falls in with the research tradition that sees control, responsibility and willpower as central to the construction of the "normal" citizen in neo-liberal societies.

\section{Constructing a divided subject}

As Douglas (1992, p. 28) makes clear in Risk and Blame, being "at risk" does not necessarily mean that it is the person at risk is to be blamed for the unfortunate "risk" identity. The following passage shows how a health consultant tries to free an overweight woman from the responsibility for her own eating habits, suggesting that it is a "voice inside [her]" and not she herself - who takes the decision to eat.
Health consultant: We have different voices inside our heads, you know, and it's the voice that wants the bad stuff that you've got to discuss things with. [Susan, the overweight woman, agrees]. Is it also like that inside your head? Do you kind of discuss things a bit?

Susan: Yes it is. Yes, every time [I eat], I know I shouldn't.

Health consultant: So you've also experienced these voices? What shall we call them? One is called Susan, so what shall we call the other one?

Susan: Well, I don't know (laughing). I don't know.

Health consultant: Well, think about that a bit. It's important to tell her: "You know this is all you'll get, and it's good", or however you want to put it. Maybe, "Right now it's me that's in charge, so I'm going to eat this". You can play around with this voice.... and then - if you unintentionally eat something that you know perfectly well know you shouldn't - you can just say, "Okay, then, you go ahead and eat your [bad food]".

In several sessions the health consultants worked on this separation of the overweight person's mind into two or more parties, just as illustrated in this extract. As well as creating an dichotomy "us" (consisting of the health consultant and the smarter part of Susan's mind) versus "them" (voices who want all the bad stuff that makes "us" fat), thus seeking to counteract the asymmetry intrinsic to the relation between the helper and the helped (the weak-willed one), and the splitting of the overweight person's mind into good and bad voices the health consultants also introduces a mind-body split. Either the voice inside the employee's head was mean (making her act against her real wishes, as in this example) or her body was mean craving all the wrong food and subsequently working against the 
real wishes of its owner. The word "real" is emphasized in order to draw attention to the morality that guides these talks. Given the perception that being overweight is a problem (i.e. following a wrong lifestyle), the problematic "at-risk" identity needs someone (a 'bad' person inside the employee) or something (a 'bad' body) to blame. Thus, despite being healthy the overweight employee was constructed not only as a person with little willpower but also as the object of external forces (the voice or body) that had produced their problematic "atrisk" identities.

\section{Conclusion}

The analyses in this paper are related to organizational research on identity processes and management dealing explicitly with power issues and employing concepts such as "dominating discourses", "normalizing discourses" "surveillance", "regulation", "control", "discipline" and "resistance" (e.g. Casey, 1999; Trethewey, 1999; Alvesson \& Willmott, 2002; Merilainen et al., 2004; Ball, 2005; Hoobler, 2005; Thomas \& Davies, 2005). The abovementioned concepts are often inspired by a foucauldian approach that treats dominating discourses, organizational practices and identity processes as three intertwined components. With the help of a governmentality-inspired analysis, I have shown how talks about private issues like body weight can be perceived as a control strategy that reflects - perhaps unintentionally - the organizational goal regarding homogenization of the work force. Despite willingness on the part of employees to engage actively in this process, regulations regarding fat bodies seem to be emerging as one of the more subtle mechanisms of contemporary organizational power.

In contemporary Western society, much of the governmentality-inspired research about the body suggests that normality, standards and acceptance all cluster round perceptions of the healthy body (e.g. Novas \& Rose, 2000; Greco, 2004). However, being overweight or "fat" does not only indicate a risky health situation, as the analysis shows: being overweight, or fat, also suggests that the individual concerned has a number of other problems as well (see also Bordo, 1993; Lebesco, 2004). For example when an overweight employee is offered all sorts of courses aimed at weight loss none of those concerned - the overweight employee, the health consultant nor the managers concerned with health initiatives in the organizations - never question the need for initiatives for achieving a healthy (read: slim) workforce. Thus being overweight or fat "naturally" calls for regulatory action on the part of the relevant social context.

Foucault's (1995) concept of "docile bodies" draws attention to organizational procedures that imply the homogenization of the individual even though most modern organizations aspire at least formally to a "pro-diversity orientation" (Ball, 2005, p. 50). Although managers often refer to the heterogeneity organization in positive terms, as they did in the present project - the variety of activities offered to overweight employees today are best understood as techniques for fostering greater homogeneity in the workforce. Just as many gender-oriented studies have explored the roles and qualities of women in organizations as opposed to those of men (Townsley, 2003) my analysis suggests that overweight persons are excluded from the respect for being different that is granted to other qualities. The critical discussion of diversity is thus relevant not only to gender, race and class - where many studies have already identified a less than genuine concern for diversity - but also to the condition of being overweight.

I have sought to demonstrate that overweight employees have become a new management object emerging from a dominating risk discourse that transforms the "at-risk" identity ascribed to overweight people into 
a problem identity, thereby creating a new problem area for management. I have argued that the management of risk identities such as the 'fat' body has consequences beyond the accepted organizational efforts to ensure the health of employees and firms. Organizational identity control involves the translation of organizational phenomena into the personal characteristics of individuals (e.g., Gubrium \& Holstein, 2001; Alvesson \& Willmott, 2002). If the organizational (and societal) narrative of fatness is a story of persons presumed to possess a variety of psychological problems, then the identity processes may generate an even greater number of marginalized people.

This new object of managerial attention involves contradiction on two levels. First, the stated goal of the organization is to minimize the "at-risk" situation of employees, but because "at-risk" identities are problematic by definition, the organization may end up with employees who have previously seen themselves as having problem identities, but who after this involvement in health strategies, may begin to see themselves as, for instance, weakwilled individuals. Second, any attempt by an organization to normalize its workforce by offering weight-loss programs to overweight employees, for example, could have the unintended effect of signaling that their ideal workforce is a slim one, which contradicts the diversity goal that many contemporary organizations entertain. By indicating a type of social figure referred to as "the somatic individual", I have shown the inherent discrepancy between on the one hand normalizing organizational practices such as working for a healthy (slim) workforce and on the other hand, prioritizing diversity. Normalization is, by definition, an anti-diversity characteristic.

The management of bodies at risk is likely to encourage ideas about the difference between the areas of an employee's life that normally belong to the public or the private domain but not to both. My analysis shows that most managers find it difficult to take up a private issue, such as a person's weight in the public domain. Despite their uneasiness, however, they go on arranging and promoting activities targeting the weight problems of their employees'. Thus, although many organizational situations such as those analyzed in this paper can be described as complex and uncertain, and although controlling employees' lifestyles is regarded as difficult, managements persist in seeking to do just this (Kärreman \& Alvesson, 2004, p. 152). And this particular form of control is one that targets social relations, emotions and the formation of identities (ibid.).

While much research on identity control emphasizes employees' work performance (and their attitudes), the present paper focuses on the employees actual bodies. This specific management goal also aims to establish a corporate identity, but one defined by the very exclusion of the targeted group (overweight employees). This specific form of identity control can thus be regarded as a dual process not only excluding overweight employees (as being problematic) but also including them (as the beneficiary of organizational interventions). Consequently, notions regarding the body and its appropriate "image" in public life are not only becoming an increasingly troubling issue for Western societies in general (Newman, 2007, p. 36), but also for management in particular.

Finally, my aim is to show the potential for applying a governmentality-inspired perspective to the analysis of identity control in contemporary organizations. While this sociological approach is not new in organizational studies, governmentality-inspired work focusing specifically on the relations between risk, morality and the body in the present paper seldom appear in organizational research. This focus has enabled me to undertake a critical examination of current management of employees' physical bodies. If health can 
be viewed as a "meta value" in contemporary Western societies (Greco, 2004), then there is - and will continue to be - a significant need for organizational research to examine the many health initiatives currently being developed in public and private work organizations.

Organization members cannot obviously be reduced to "passive consumers of managerially designed and designated identities" (Alvesson \& Willmott, 2002, p. 621). On an organizational level the practices is obviously complex and varied, but organizations exist in specific societies that endorse specific "truths" at specific times (e.g. risk societies endorsing health as a meta value). In this paper, I have tried to problematize (and explain) the current pursuit of the healthy (slim) body that is coming to represent a "natural" goal for many work organizations to pursue. I have sought to show that managers, health consultants and overweight employees cannot escape the dominating risk discourse that automatically picks out certain "problem" individuals as being in need of management. I am not suggesting that work organizations are becoming systems of "total control" (cf. Gabriel 1999, p. 186), but only that organization and society are two inseparable entities making sociological approaches that attempt to produce a coherent theory of our society, like the work done on risk society, very stimulating for organizational research.

\section{References}

Alvesson, M. \& Willmott, H. (2002). Identity Regulation as Organizational Control: Producing the Appropriate Individual, Journal of Management Studies 39(5): 619-44.

Ashcraft, K. L. (2000). Empowering "Professional" Relationships: Organizational Communication Meets Feminist Practice, Management Communication Quarterly 13(3): 347-92.

Ball, K. (2005). Organization, Surveillance and the Body: Towards a Politics of Resistance, Organization 12(1): 89-108.

Bordo, S. (1993). Unbearable Weight: Feminism,
Western Culture, and the Body. Berkeley, CA: University of California Press.

Brewis, J., Hampton, M. \& Linstead, S. (1997). Unpacking Priscilla: Subjectivity and Identity in the Organization of Gendered Appearance, Human Relations 50(10): 1275-1304.

Casey, C. (1999). "Come, Join Our Family": Discipline and Integration in Corporate Organizational Culture, Human Relations 52(2): 155-78.

Dean, M. (1999a). Risk, calculable and incalculable. In D. Lupton (Ed.), Risk and sociocultural theory: New directions and perspectives (pp. 131-59). Cambridge: Cambridge University Press.

Dean, M. (1999b). Governmentality. Power and Rule in Modern Society. London: Sage.

Douglas, M. (1966). Purity and Danger: An Analysis of Concepts of Pollution and Taboo. London: Routledge \& Kegan Paul.

Douglas, M. (1992). Risk and Blame. London: Routledge.

Ericson, R. V. \& Doyle, A. (2003). Risk and Morality. In A. Doyle \& R.V. Ericson (Eds.), Risk and Morality (pp.1-10). Toronto: University of Toronto Press.

Foucault, M. (1995). Discipline and punish: The birth of the prison. New York, NY: Vintage Books.

Gabriel, Y. (1999). Beyond Happy Families: A Critical Reevaluation of the Control-Resistance-Identity Triangle, Human Relations 52(2): 179-203.

Gavison, R. (1992). Feminism and the Public/Private Distinction, Stanford Law Review 45(1): $1-45$.

Goffman, E. (1968). Asylums. Essays on the Social Situation of Mental patients and Other Inmates. London: Penguin.

Gordon, C. (1991). Governmental rationality: An introduction. In G. Burchell, C. Gordon \& P. Miller (Eds.), The Foucault Effect: Studies in Governmentality (pp. 1-51). Hemel Hempstead: Harvester Wheatsheaf.

Greco, M. (2004). The Politics of Indeterminacy and the Right to Health, Theory, Culture \& Society 21(6): 1-22.

Gubrium, J. F. \& Holstein, J. A. (1997). The New Language of Qualitative Method. Oxford: Oxford University Press. 
Gubrium, J. F. \& Holstein, J. A. (2001). Introduction: Trying Times, Troubled Selves. In J. F. Grubrium \& J.A. Holstein (Eds.), Institutional Selves: Troubled Identities in Organizational Context (pp. 1-22). Oxford: Oxford University Press.

Hassard, J., Holliday, R. \& Willmott, H. (2000). Introduction: The Body and Organization. In J. Hassard, R. Holliday \& H. Willmott (Eds.), Body and Organization (pp. 1-14). London: Sage.

Holstein, J. A. \& Gubrium, J. F. (1997). Active Interviewing. In D. Silverman (Ed.), Qualitative Research. Theory, method and practice (pp. 113-30). London: Sage.

Hoobler, J. M. (2005). Lip Service to Multiculturalism: Docile Bodies of the Modern Organization, Journal of Management Inquiry 14(1): 49-56.

Järvinen, M. (2001). Accounting for Trouble. Identity Negotiations in Qualitative Interviews with Alcoholics, Symbolic Interaction 24(3): 263-84.

Kärreman, D. \& Alvesson, M. (2004). Cages in Tandem: Management Control, social Identity, and Identification in a Knowledge-Intensive Firm, Organization 11(1): 149-75.

Lebesco, K. (2004). Revolting Bodies? The struggle to redefine fat identity. Boston, MA: University of Massachusetts Press.

Lemke, T. (2001). The birth of bio-politics: Michel Foucault's lecture at the Collège de France on neo-liberal governmentality, Economy and Society 30(2): 190-207.

Linstead, A. \& Brewis, J. (2004). Editorial: Beyond Boundaries: Towards Fluidity in Theorizing and Practice, Gender, Work and Organization 11(4): 355-62.

Lister, R. (1997). Citizenship: Feminist Perspectives. Basingstroke: Macmillan.

Lister, R. (2001). Citizenship and gender. In K. Nash \& A. Scott (Eds.), The Blackwell Companion to Political Sociology (pp. 323-31). Oxford: Blackwell.

Loseke, D. R. (1999). Thinking About Social Problems: An Introduction to Constructionist Perspectives. New York, NY: Aldine de Gruyter.

Lupton, D. (1999a). Introduction: Risk and sociocultural theory. In D. Lupton (Ed.), Risk and sociocultural theory: New directions and perspectives (pp. 1-11). Cambridge: Cambridge University Press.

Lupton, D. (1999b). Risk and the ontology of pregnant embodiment. In D. Lupton (Ed.), Risk and sociocultural theory: New directions and perspectives (pp. 59-85). Cambridge: Cambridge University Press.

Lupton, D. (2005). Risk. London: Routledge.

Merilainen, S., Tienari, J., Thomas, R. \& Davies, A. (2004). Management Consultant Talk: A Cross-Cultural Comparison of Normalizing Discourse and Resistance, Organization 11(4): 539-64.

Mik-Meyer, N. (2009). Sociological Theory in Situated Practice - sociological categories in everyday discourse. In G. Cooper, A. King \& R. Rettie (eds.) Sociological Objects: reconfiguration of social theory. London: Ashgate. (in press).

National Audit Office (2001). Tackling Fatness in England. Report by the Comptroller and Audit General HC 220 Session. 2000-2001: 15 February 2001. London: The Stationery Office.

Newman, J. (2007). Rethinking 'The Public' in Troubled Times. Unsettling State, Nation and the Liberal Public Sphere, Public Policy and Administration 22(1): 27-47.

Novas, C. \& Rose, N. (2000). Genetic risk and the birth of the somatic individual, Economy and Society 29(4): 485-513.

O'Malley, P. (2000). Uncertain subjects: risk, liberalism and contract, Economy and Society 29(4): 460-84.

Orbach, S. (1978). Fat Is a Feminist Issue. New York, NY: Berkley Books.

Rose, N. (1996). The death of the social?, Economy and Society 25(3): 327-56.

Rose, N. (2001). The Politics of Life Itself, Theory, Culture \& Society 18(6): 1-30.

Silverman, D. (2003). Analysing Talk and Text. In N. K. Denzin \& Y. S. Lincoln (Eds.), Collecting and Interpreting Qualitative Materials (pp. 340-62). Thousand Oaks, CA: Sage.

The Ministry of Interior and Health (2002). Sund hele livet (Healthy all life). Copenhagen: The Ministry of Interior and Health.

Thomas, R. and Davies, A. (2005). Theorizing the Micro-politics of Resistance: New Public 
Management and Managerial Identities in the UK Public Services, Organizational Studies 26(5): 683-706.

Townsley, N. C. (2003). Review Article: Looking Back, Looking Forward. Mapping the Gendered Theories, Voices, and Politics of Organization, Organization 10(3): 617-39.

Trethewey, A. (1999). Disciplined Bodies: Women's Embodied Identities at Work, Organizational Studies 20(3): 423-50.

Valentine, G. (2002). In-corporations: Food, Bodies and Organizations, Body \& Society 8(2): $1-20$.

Wilson, F. (1996). Research Note: Organizational Theory: Blind and Deaf to Gender?, Organizational Studies 17(5): 825-42.

World Health Organization (2006a). 10 things you need to know about obesity. Copenhagen: WHO Regional Office for Europe.

World Health Organization (2006b). WHO European Ministerial Conference on Counteracting Obesity. European Charter on counteracting obesity. Copenhagen: WHO Regional Office for Europe.

World Health Organization (2006c). Highlights on health in Denmark. Copenhagen: WHO Regional Office for Europe. 